RESEARCH ARTICLE

\title{
The Repertoire and Structure of Vocalizations of the Southern Magpie Robin (Copsychus saularis ceylonensis) in the Kandy Region, Sri Lanka
}

\author{
Saumya Wanniarachchi* and Chaminda S. Wijesundara \\ Department of Zoology, University of Peradeniya, Peradeniya, Sri Lanka
}

\begin{abstract}
Bird vocalizations could be used to analyze various ecological aspects and hypotheses as the environment affects the evolution of acoustic signals. Oriental Magpie Robin (Copsychus saularis ceylonensis) is one such ideal candidate for ecological studies in Sri Lanka since it shows a wide variety of interesting behaviors including elaborative vocalizations. Yet, there has been hardly any scientific studies directed towards the vocalization activities or on the ecological aspects of this bird. Thus, the aim of this study was to investigate the vocalization behavior and its physical parameters in order to identify the characteristics that need further studying and to understand the role of this bird in its habitats. The study was carried out in two sites, Peradeniya and Balagolla located in the Central Province of Sri Lanka between February and August, 2015. Behavioral observation was done according to the focal animal sampling method, and continuous recording was used as the sampling rule. Vocalizations were video recorded using a Canon SX 700 digital camera containing a built-in microphone. Recorded acoustic data were transcribed and a sonogram was obtained for each vocalization pattern. Parameters such as maximum frequency, minimum frequency duration, and intervals between phrases were used to describe and analyze the physical features of the vocalization. The dominant call of magpie robin was an inflection note. Alarm call had a physical structure fulfilling the requirements of a mobbing call. The structure of the territorial songs of the Magpie Robin ranged from simple to complex notations and holds a physical structure conducive to communicating in open habitats. Males aggressively defended territory boundaries by the usage of complex and elaborate songs.
\end{abstract}

Keywords: Birds, Acoustics, Oriental Magpie Robin, Mobbing calls, Bird songs.

\section{INTRODUCTION}

Birds use a variety of vocal signals in their communication (Payakkhabut, 2012). These signals are used in communicating for kin recognition, mate choice and attraction, territorial defense, parent offspring communication, as well as for the intraspecific communication (Ritchison, 1983; Geoff, 1996; Johnson and Kermott, 1991; Briefer et al., 2010; Charrier et al., 2001). Vocalizations range from short clicks to long tinkling melodies, and the frequencies vary from deep infra sounds to higher pitched inaudible sounds (Gill, 2007; Payakkhabut, 2012). Complexity of the vocalization and the feature it anticipated to share are important to be preserved yet the environmental variations could alter the original state of these vocal signals (Briefer et al., 2010). Thus, the bird vocalization is an ideal variable to be investigated in testing different ecological hypotheses such as Acoustic Adaptation Hypothesis (Graham et al., 2016).

Among the birds who display complex vocalization behaviors, the Oriental Magpie Robin (Copsychus saularis ceylonensis) is distinguished for its interesting intraspecific and interspecific behaviors, song performances, and complex song structure (Bhatt et al., 2014; Ali and Ripley, 2001). The song structure has completely different acoustic characteristics from one syllable to another (Jiang, 2003). Magpie Robins are one of the most common birds found throughout the Indian Sub-continent (Grimmett et al., 2011). Sri Lanka and southern parts of India share the peculiar race known as the Southern Magpie Robin or the Oriental Magpie Robin (Copsychus saularis ceylonensis) (Clements et al., 2015). In Sri Lanka, the Southern Magpie Robin (herein after referred to as the Magpie Robin) is found throughout the island and is a common resident in gardens, cultivations, scrub, and open forests throughout Sri Lanka (Henry, 1971; Harrison, 2011; Warakagoda et al., 2012). Hence this bird would be an ideal candidate species in testing ecological 
hypotheses inked to vocalization in Sri Lanka, yet there has been hardly any scientific research on the vocalization activities of this bird. Thus, very little information is available on its vocalization parameters and characteristics and its ecological significance in Sri Lanka especially with the different habitats being occupied by this bird species. Therefore, much work remains to be done on this species and its signaling role in local ecosystems. Hence, a detailed vocal behavioral study on different aspects of vocalization of this interesting bird will be a valuable addition to future Sri Lankan ecological studies linked to vocalization.

The main objective of the present study was to construct a comprehensive record of the vocalization behavior of Magpie Robin, obtaining sonograms for the acoustic data and to analyze the physical characteristics of common vocalization patterns and identify which aspects the future studies should be directed in ethological and ecological aspects of this bird.

\section{MATERIALS AND METHODS}

\section{Study Area}

Two study sites, located in Balagolla $\left(7^{\circ} 28^{\prime} \mathrm{N}\right.$, $\left.80^{\circ} 71^{\prime} \mathrm{E}\right)$ and Peradeniya $\left(7^{\circ} 26^{\prime} \mathrm{N}, 80^{\circ} 59^{\prime} \mathrm{E}\right)$ in the Kandy District, Sri Lanka were selected for this study. The elevations of the two sites are 545 $\mathrm{m}$ and $500 \mathrm{~m}$ ASL, respectively and the mean annual temperature is $24{ }^{\circ} \mathrm{C}$ while the humidity is $70 \%$ to $79 \%$. Mean Annual rainfall of the two sites are higher than 2,000 $\mathrm{mm}$ (Department of Meterology, 2014).

The study site in Balagolla is a road side suburban habitat with large home gardens. Magpie Robins are frequently seen visiting these home gardens and utilizing the resources within the area. The second study site was the garden habitats within the campus of the University of Peradeniya. The area has a high diversity of avifauna including Magpie Robins and other bird species (Wijesundara and Santiapillai, 2001).

\section{Behavior sampling}

Preliminary observations in the two study sites were carried out in February, 2015. Four individuals (two males and two females) from each study site were considered in obtaining the percentage of vocal activity from the total diurnal activity. Each individual was observed for approximately 12 hours of time according to the focal animal sampling method (Martin and Bateson, 2007; Altmann, 1974) and recorded the animal's behavior. During this period, vocalization and other behaviors were also noted (e.g. perching, foraging, feeding, nest making, etc.). Once an individual was selected, it was followed until the individual moved completely out of sight. If the focal individual moved completely out of sight recording was stopped until it is visible again. Such interruptions were recorded as 'time out'. Continuous recording was used as the recording rule where each existence of the behavior patterns was recorded together with the time of their occurrence, according to Martin and Bateson (2007). The final measures were calculated according to the time for which the focal individual was visible.

To score behavior JWatcher V 1.0 behavior scoring software (Blumstein et al., 2007) was used. The summarized behavior score files were converted to Microsoft Excel work sheets and analyzed. Time budgets for the Magpie Robin were constructed using the 'StateAllDur' (State Analysis, All, Duration) statistics obtained by the summary of behavior scoring. 'StateAllDur' is calculated for the duration of the states and all of the durations are included in the calculation (Blumstein et al., 2007). In the 'StateAllDur' Total Time (TT) option was used to obtain the percentage of vocal activity from the total diurnal activity.

\section{Vocal recording}

Vocal recordings were carried out from March, 2015 to August, 2015 in both study sites, between sunrise to sunset on each sampling day, for three days a week. Peak observation hours were between 0600-0900h and 1500-1800h additionally opportunistic sampling was carried out before and after the peak observation hours to identify the earliest and the latest hours of vocal activity. Vocal activity of 22 individuals including 6 adult males, 7 adult females, 5 sub adults and 4 fledglings were recorded in two study sites.

Vocalizations (dominant call, songs, and alarm calls) of Magpie Robins were video recorded using a Canon SX 700 digital camera containing a built-in microphone. This instrument digitized the sound waves at a sampling rate of $48 \mathrm{kHz}$ with a 16-bit resolution. 581 minutes and 483 minutes from Balagolla Study area and Peradeniya study area were 
recorded respectively (1064 minutes of video recording collectively).

\section{Sound analysis}

Recorded acoustic data were transcribed from video files to Wave (*.wav) files using Format Factory Version 3.6.0 (Hao, 2015) open source video sound converter. A sonogram was obtained for each vocalization pattern using Raven Lite Version 1.0 software (Charif, 2006). Parameters such as maximum frequency, minimum frequency duration, and intervals between phrases were used to describe and analyze the physical features of the vocalizations. For the analysis of the structure and the composition of the vocalization, noise reduction was carried out using Raven Lite Version 1.0. Calls were compared including calling durations, after the removal of undistinguishable recordings through the sonograms. 154 vocal records were used in sonogram analysis and these vocalizations included 57 songs (320 minutes), 79 dominant calls (242 minutes), 27 alarm calls (73 minutes) and 6 chatters (45 minutes).

\section{RESULTS}

\section{Vocalization Structure and Behavior}

Our study indicates that approximately $34 \%$ (Males 47-51\%, Females 16-20\%) of diurnal time was spent in vocalizations by these birds. Male Magpie Robin showed a great repertoire of songs compared to females. The vocal behavior of the Magpie Robin can be categorized into several types based on its usage and the physical structure. These are the 'dominant call', 'alarm call', 'song' and 'chatter'(Table 1).

The dominant call, the most common call observed in the study, was a single noted whistle that sounded similar to a Tweet and was recited by both male and female birds as well as the sub adult Magpie Robins (Figure $1 \mathrm{~A}$ ). The phase duration was $1.0066 \mathrm{~s} \pm 0.4761$, while the minimum frequency was $2.1 \mathrm{kHz} \pm 0.3 \mathrm{kHz}$ and the maximum frequency was $5.5 \mathrm{kHz} \pm 1.7 \mathrm{kHz}$. The number of notes on a phrase was $11.9 \pm 5.9$. The dominant call element or note shows an inflection in the frequency where the pitch is increased with time (Figure $1 \mathrm{~A}$ ). The minimum frequency of the dominant call note ranged from 4.1-4.2 kHz, while the maximum frequency ranged from $5.8-6.0 \mathrm{kHz}$. The call note is composed of three clearly visible harmonics (Figure 1B) and the mean note duration was $0.25 \mathrm{~s}$.

The alarm call is a harsh screech-like noisy call with a spitting-like sound, recited by both males and females, including fledglings (Figure 1B). The note is monotonous and noisy with numerous harmonics. The lowest detectable frequency of the alarm call ranged from 1.3-1.6 $\mathrm{kHz}$ and the highest detected frequencies ranged from 13-15 kHz. Alarm calls were observed deliverd during presence of the predators such as snakes and cats and also in the late evening hours without any possible alarming context. Spectrogram of the alarm call had a short duration (less than $0.5 \mathrm{~s}$ ) of broad frequency structure. In one occasion Magpie Robins were observed delivering alarm calls with a mixed species group comprising of Yellow-billed Babblers (Turdoides affinis), Purple-rumped Sunbirds (Leptocoma zeylonica), a Scalybreasted Munia (Lonchura striata), Great Tit (Parus major), Red-vented Bulbul (Pycnonotus cafer), Common Tailor Bird (Orthotomus sutorious), and an Indian Palm Squirrel (Funambulus palmarum).

Table 1: Parameters of the vocalizations of Oriental Magpie Robin (Mean \pm SD), * A phrases or intervals cannot be identified in the chatter.

\begin{tabular}{lllll}
\hline & Song & Dominant call & Alarm Call & Chatter \\
\hline Number of Individuals & 6 & 15 & 11 & 4 \\
\hline Number of Vocal Samples & 42 & 79 & 27 & 6 \\
\hline Phrase/ Note duration (s) & $1.0066 \pm 0.47$ & $0.2500 \pm 0.05$ & $0.500 \pm 0.2$ & $*$ \\
\hline Minimum frequency (kHz) & $2.1 \pm 0.3$ & $4.1 \pm 0.2$ & $1.3 \pm 0.3$ & $8.2 \pm 0.5$ \\
\hline Maximum frequency (kHz) & $6.5 \pm 1.7$ & $5.8 \pm 0.4$ & $13.0 \pm 1.5$ & $1.5 \pm 0.2$ \\
\hline Number of notes on a phrase & $11.9 \pm 5.9$ & 1 & 1 & $*$ \\
\hline
\end{tabular}



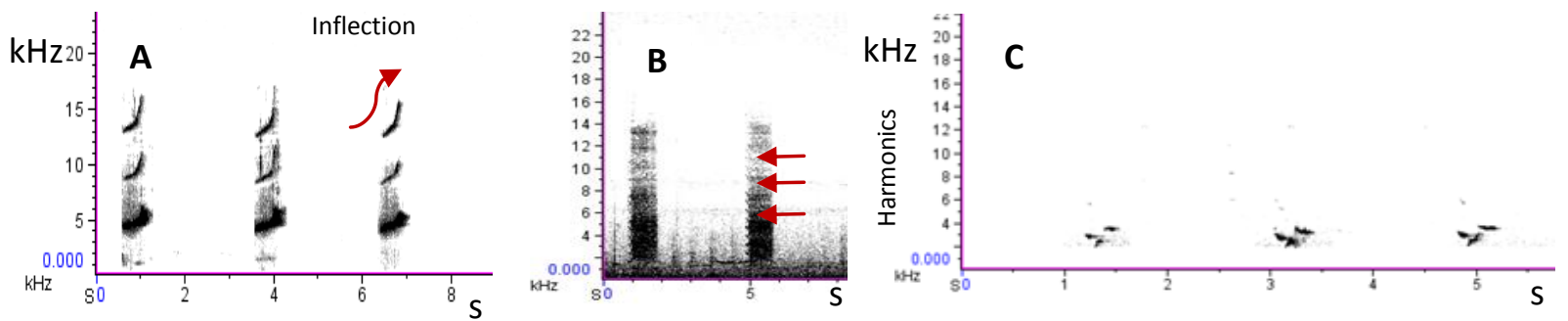

Figure 1: A. Sonogram of the dominant call of Magpie Robin (phrase duration - 1.0066s $\pm 0.4761 \mathrm{~s}$, minimum frequency $2.1 \mathrm{kHz} \pm 0.3 \mathrm{kHz}$, maximum frequency- $5.5 \mathrm{kHz} \pm 1.7 \mathrm{kHz}$, number of notes on a phrase $-11.9 \pm 5.9$ ), $\mathbf{B}$. alarm call (lowest frequency - 1.3-1.6 kHz, highest detected frequencies - 13-15 kHz, duration less than $0.5 \mathrm{~s}$ ) C. simple phrased territorial call (number of notes -3 , phrase duration- $0.61 \mathrm{~s}$, frequency range- $1.8-3.8 \mathrm{kHz}$ ).

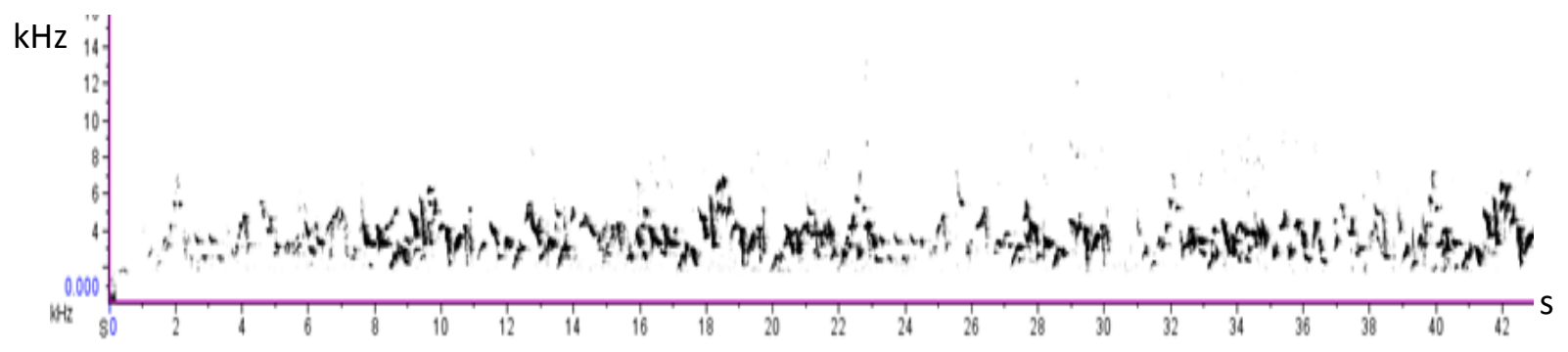

Figure 2: A chatter of Magpie Robin with an unorganized phrase like note structures (frequency range $8.2 \mathrm{kHz}-1.5 \mathrm{kHz}$ ).

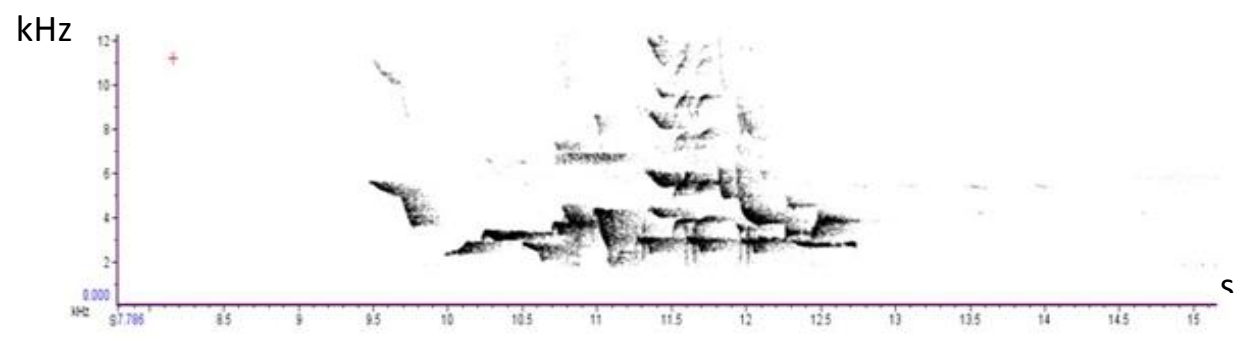

Figure 3: Sonogram of a single phrase of a complex and elaborative song, frequency range-1.9-6.0 kHz, number of identifiable notes -13 , phrase duration $-3.4 \mathrm{~s}$.

A song is a collection of repetitive phrases having different types of notes, usually recited by the male Magpie Robins as part of their territorial display, two males who are fighting to establish territorial boundaries could be seen using songs to establish their territory by singing contrary to each other, occasionally females could be seen performing songs in the presence of males during courtship displays. Male Magpie Robins showed a great variety of singing. The most complex and elaborative song observed shows repetitive phrases of a complex notation with harmonics and overlapping of notes with duet notations towards the end. The song consisted of 13 different notes with $3.4 \mathrm{~s}$ duration, and the frequency ranged from 1.9-6.0 $\mathrm{kHz}$ (Figure 3). Less elaborative and less complex songs were recorded from all individual males (Figure 1. C). The simplest type of song observed involved three notes and a phrase duration of $0.61 \mathrm{~s}$ and a frequency range of 1.8$3.8 \mathrm{kHz}$.

It was observed that male Magpie Robins started the vocalization activity early in the morning at their roosting sites (earliest vocalization observed was $0415 \mathrm{~h}$ ), much earlier than the other birds in both the study areas, while perching on their roosting sites. As ambient light increased, they moved to nearby locations such as tall trees, television antennas, tall buildings, utility poles, and telephone wires which probably enhanced their visibility and audibility to conspecifics. In males, elaborate singing was observed throughout the breeding season (early April to late July) starting from dawn until dusk, prominently during the early hours of the morning. Near the nesting sites, males were 
observed perching on relatively tall substrates delivering lengthy songs while being alert. During the breeding season, males defend their territorial rights. Once the rival or the intruder entered the territory, male would start to sing and use the alarm vocalization, or a combination of both, and if the intruder did not respond to the warnings there was a series of tail jerking and short flight displays with singing, which would lead to a noisy fight where both parties would sing or alarm continuously.

A more complex and an unorganized type of call (Figure 3) was observed in male Magpie Robins specially during perching. This is known as a chatter. During the chattering, no other Magpie Robins were observed in the surroundings. Chatter is simply a song like elongated vocalization without silent intervals. Notations could be repetitive or highly unorganized frequency range of chatters were between $8.2 \mathrm{kHz}$ and $1.5 \mathrm{kHz}$. Majority of the chatters were observed throughout the rainy weather on the first half of the day during the study period.

Similarly, females were seen reciting dominant and alarm calls starting from the early hours of dawn in analogous dwellings to males but no songs were reported during these periods. In females, songs other than the normal vocalization were exhibited only during the courtship dances. To compare the time devoted for calling a Mann-Whitney test was used, a significant difference between male and female Magpie Robins was observed $(\mathrm{W}=926.0, \mathrm{p}<$ 0.05 ). The males devoted a greater time in vocalization compared to the females.

\section{DISCUSSION}

The Magpie Robin is a common bird species found throughout the home garden habitats (Warakagoda et al., 2013) and its behavior can be easily observed by keeping close proximity to the bird without alarming. Thus, they are an ideal species to test ecological frameworks such as Acoustic Adaptation Hypothesis.

Phrases of the songs could vary according to the individual as well as situations such as the ambient noise (Oden, 2013; Klump and Shalter, 1984). Male Magpie Robins displayed a wide variety of songs and these songs are used in various activities such as defending the territories or attracting mates during courtship displays, similar to the bird species such as White-rumped Shama (Copsychus malabaricus leggei) and Indian Robin (Saxicoloides fulicatus) (Perera, 2000; Wikramasinghe and Dilhari, 2013)

The mean phrase duration of the male Magpie Robin in the study area was lower compared to the mean phrase duration reported for the same species in Rajasthan, India (5.14 \pm 2.2s) (Koli, 2014). However, the habitats are different from each other in two places (Wildlife Sanctuary in Rajasthan compared to suburban surroundings in the present study) and geographic variations give rise to changes in bird songs (Podos \& Warren, 2007). This could be reasons to variations observed in phrase durations.

These phrases included inflected notes. The basic structure of majority of fundamental notes observed had a broad duration (at least $0.5 \mathrm{~s}$ ) and a narrow frequency. In birds, males tend to recite long range non directional songs spreading far away from the speaker allowing the call to be received by many audiences at the same time (Boncoraglio and Saino, 2007). Complex acoustic signals with high frequencies tend to get degraded in structurally multipart habitats such as dense forests (Boncoraglio and Saino, 2007). Magpie Robins inhabit suburban habitats with ample amount of open spaces, and they utilize relatively tall substrates. Thus, the probability of the song getting degraded is less. Hence, the habitat structure might have played a role in modeling the vocal repertoire of the Magpie Robin. Further analysis is required to describe the exact relationship between the habitat structure and the vocal repertoire of the Magpie Robin.

A typical urban characteristic is the high level of ambient noise, which presents difficulties for animals that use vocal communication, (Hu and Cardoso, 2009), thus further studies are needed to distinguish the function and the ambient noise in Magpie Robin vocalization. Adjustments and shifts in frequencies, phrases and notations could give rise to dialects (Oden, 2013), thus with the long range distribution throughout the island this birds vocalization could be a fine sources for investigating song dialect systems in Sri Lankan birds. 
Magpie Robins started singing from early hours of the day $(0415 \mathrm{~h})$, which is earlier than the other birds in the study area and is consistent with observations from other populations (Bhattacharya et al., 2008; Bhatt et al., 2014; Koli, 2014). With the change of the environment, changes in the behavior of animals can be observed. Change of the behavior responding to the 24-h cycle of light and dark change is known as circadian rhythms (Gill, 2007). Change of light intensity is a stimulus controlling the commencement and termination of diurnal rhythms (Koli, 2014). According to Roenneberg and Russel (1997), initiation of the singing in Magpie Robins could be a result of a finely modified sensory system responding to the rapid changes in the twilight hours. Communication at this time of the day is particularly important for mate choice, and intra-sexual competition (Berg et al., 2006). Characteristics of dawn song performance therefore may have evolved as honest signals of male quality (York et al., 2014). Female song birds asses males based on the repertoire size, duration of singing and ability of singing physically challenging songs (Ballentine et al., 2004). Thus, in a similar context Magpie Robins might be using the dusk or dawn songs and calls to exhibit better qualities than the neighbors. Males use the long and elaborate vocalizations to attract females and the territorial calls to defend the boundaries of the territory (Bhatt et al., 2014). Male song is known to be essential in the mate choice in birds, since the different song features reflect different singing traits of the singer (Darolová et al., 2012) and it could be an honest indication of male quality which can be directly assessed by the females.

There was a significant difference according to the Mann-Whitney test $(p<0.05)$ in the call devotion time as well as the temporal occurrence of the song in male and female. Female tends to be less vocal than the male. Males were highly vocal, spending a high proportion of time (49\% of total time observed) in singing compared to female (13\% of total time observed). Males use the long and elaborate vocalizations to attract females and the territorial calls to defend the boundaries of the territory (Bhatt et al., 2014). Magpie Robins tend to recite their territorial songs perching on relatively tall substrates within their territory margins. If the songs are uttered within a surrounding with obstacles the structural changes could occur in the acoustic signal such as scattering and refracting (Morton, 1986). Thus, Magpie Robins could be using the tall perching spots to reduce the degradation of the acoustic signal in order to spread the acoustic signal to other rival males and for potential mates.

Among the vocalization types of Magpie Robin, alarm calls were recited by both sexes. Alarm calls are given by birds to warn others of the presence or approach of a predator (Klump and Shalter, 1984; Marler, 1957; Johnson et al., 2003). Spectrogram of the alarm call of Magpie Robin exhibited a short duration broad frequency structure, which allows eavesdroppers to detect the direction and distance of the caller (Gill, 2007). This probably facilitates to easily rally the other individual to help chase out the threatening intruder. Such calling types are also known as mobbing calls (Johnson et al., 2003). This structure was similar to the alarm calls recited by the Ashy-headed Laughing Thrush (Garrulax cinereifrons), Orange-billed Babbler (Turdoides rufescens), and Racket-tailed Drongo (Dicrurus paradiseus) in a mixed species flock in Sinharaja Forest Reserve (Goodale and Kotagama, 2005). The observation of Magpie Robins delivering alarm calls with mixed species groups in the neighborhood could be an indicator that predator detection and avoidance could be key driving force for the formation of mixed species groups in the region.

Thus, it can be concluded that these Magpie Robin recites several types of calls in addition to its dominant "tweet" call, which can be categorized as Alarm Calls, Songs and Chatters. Vocalization of Magpie Robin could be utilized in investigating male quality by examining the songs structures, evolution of dialects and the mobbing aspect of the alarm call of this bird in Sri Lanka.

\section{ACKNOWLEDGEMENTS}

We thank the Department of Zoology, University of Peradeniya for providing equipment and other facilities for this study. We are grateful to Tharangi Hettiarachchi, Dilan Chathuranga, Chamalka Dulmini, and Sewwandi Wijesuriya for their assistance during field work. Thanks are also due to Bhagya Herath for her support with spectrogram analysis. 


\section{REFERENCES}

Ali, S. and Ripley, S. (2001). Handbook of the Birds of India and Pakistan 9th ed., Oxford University Press

Altmann, J. (1974). Observational Study of Behavior: Sampling Methods. Behaviour. 49(3):227-266.

Ballentine, B., Hyman, J. and Nowicki, S. (2004). Vocal performance influences female response to male bird song: An experimental test. Behavioral Ecology. 15(1):163-168.

Berg, K.., Burmfield, R.T. and Apanius, V.(2006). Physiological and ecological determinants of neotropical dawn call. Proceedings of royal society of London. B 273:999-1005.

Bhatt, D., Sethi, V. K. (2014). Some notes on the breeding behaviour of the oriental magpie robin (Copsychus saularis) from Uttarakhand, India 9(1):112-119.

Bhattacharya, H., Cirillo, J. and Todt, J. (2008). Song Performance Rules in the Oriental Magpie Robin (Copsychus salauris). Our Nature. 5(1):1-13.

Bioacoustics Research Program, (2003). Raven LIte 1.0 .

Blumstein, D.T., Daniel, J.C. and Evans, C.S., (2007). JWatcher.

Blumstein, D.T., Daniel, J.C. and Evans, C.S., (2007). JWatcher 1.0: An introductory user's guide, Massachusetts, U.S.A: Sinauer Associates, Inc.

Boncoraglio, G. and Saino, N., (2007). Habitat structure and the evolution of bird song: A metaanalysis of the evidence for the acoustic adaptation hypothesis. Functional Ecology. 21(1):134-142.

Briefer, E., Oseijuk, T. S., Rybak, F. and Aubin, T. (2010). Are bird song complexity and song sharing shaped by habitat structure? An information theory and statistical approach. Journal of Theoretical Biology. 262(1):151-164.

Charif, R.A., (2006). Raven Lite10 Users Guide, Ithaca, NY: Cornell Lab of Ornithology. Available at: $\quad$ papers://c32175d7-d89d-4b27-af31837cef862ad3/Paper/p499.

Charrier, I., Mathevon, N. and Jouventin, P. (2001). Acoustic Communication in a Black-Headed Gull Colony: How Do Chicks Identify Their Parents? Ethology. 107(11):961-974.

Clements, J. F., Schulenberg, M. J., Lilff, M. J., Roberson, D., Fredericks, T. A., Sulvian, B.L. and Wood, C. L. (2015). Clements checklist of birds of the world: v2015, Available at: http://www.birds.cornell.edu/clementschecklist/do wnload/.

Darolová, A., Kristofik, J., Hoi, H, Wink, M. (2012). Song complexity in male marsh warblers: does it reflect male quality? Journal of Ornithology. 153(2):431-439.
Department of Meteorology. (2014). Climate in Sri Lanka (2014). Department of Meteorology Sri Lanka. Available at: http://www.meteo.gov.lk.

Geoff, S. (1996). Bird Songs of Britain and Northern Europe, London: Harper Collins Publications.

Gill, F.B. (2007). Ornithology 3rd ed., New York: W.H. Freeman and Company.

Goodale, E. and Kotagama, S.W. (2005). Alarm calling in Sri Lankan mixed-species bird flocks. The Auk. 122(1):1-13.

Graham, B.A. Sandoval, L., Dabelsteen, T. and Mennill, D. (2016). A test of the Acoustic Adaptation Hypothesis in three types of tropical forest: degradation of male and female Rufousand-white Wren songs. Bioacoustics. 4622(May):1-25.

Grimmett, R., Inskipp, C. and Inskipp, T. (2011). Birds of the Indian Subcontinent 2nd ed., Oxford University Press.

Hao, C.J., 2015. Format Factory 3.6.0.

Harrison, J., (2001). A Field Guide To Birds of Sri Lanka 2nd ed., London: Oxford University Press,.

Henry, G.M. (1971). A Guide to the Birds of Ceylon. 2nd Edn., London.: Oxford University Press.

$\mathrm{Hu}$, Y. and Cardoso, G.C. (2009). Are bird species that vocalize at higher frequencies preadapted to inhabit noisy urban areas? Behavioral Ecology. 20(6):1268-1273.

Jiang, S.R. (2003). Vocal behavior of Oriental Magpie Robin in China.pdf. Sichuan Journal of Zoology. 22(3):144-0146.

Johnson, F. R. McNaughton, J.E. Shelly, C.D., Blumstein, D. T. (2003). Mechanisms of heterospecific recognition. Australian Journal of Zoology. 51:577-585.

Johnson, L. and Kermott, L. (1991). The Function of Song in Male Houes Wrens "Troglodytes aedon." Behaviour. 116:190-206.

Klump, G.M. and Shalter, M., (1984). Acoustic behaviour of birds. Zeitschrift für Tierpsychologie. 66: $189-228$.

Klump, G.M. and Shalter, M.D. (1984). Acoustic behaviour of birds and mammals in the predator context. Zeitschrift für Tierpsychologie. 226:189226.

Koli, K. (2014). Morning territorial calls of male oriental magpie robin (Copsychus saularis). TAPROBANICA: The Journal of Asian Biodiversity. 6(1):60-62.

Marler, P. (1957). Communication signals of birds. Behaviour. 11:13-39.

Martin, P. and Bateson, P. (2007). Measuring Behavior. Cambridge: Cambridge University Press: 24-71. 
Morton, E.S. (1986). Predictions from ranging hypothesis for the evolution of long distance signals in birds. Behaviour. 99:66-58.

Oden, A.I. (2013). Changes in Avian Vocalization Occurrence and Frequency Range During the Winter. University of Nebraska.

Payakkhabut, S. (2012). Vocal Communication in Sooty-headed Bulbul; Pycnonotus aurigaster. 6(4):415-420.

Perera, M.S.J. (2000). Preliminary study on behavior, diurnal activity and territoriality of black robin. B.Sc. Thesis. Sabaragamuwa University of Sri Lanka.

Podos, J. and Warren, P.S. (2007). The Evolution of Geographic Variation in Birdsong. Advances in the Study of Behavior. 37(7):403-458.

Ritchison, G. (1983). The Function of Singing in Female Black Headed Grosbeaks. The Auk. 100:105-116.
Roenneberg, T. and Russel, G.F. (1997). Twilight times: light and circadian systems. Photochemistry and photobiology. 66(5):549-561.

Warakagoda, D., and Grimmett, R. (2013). Birds of Sri Lanka First Edit., London: Christopher Helm.

Wijesundara, C. and Santiapillai, C. (2001). The diversity of resident birds in the campus of the University of Peradeniya, Sri Lanka. Journal of Science, Eastern University of Sri Lanka. 2(1):6982.

Wikramasinghe, S. and Dilhari, W.M.M. (2013). Teritoriality of Copsychus malabaricus in Western Part of the Mihinthale Sanctuary, Sri Lanka. International Forestry and Environment Symposium. p.2013.

York, J.E., Young, A.J. and Radford, A.N. (2014). Singing in the moonlight: dawn song performance of diurnal bird varies with lunar phase. Biology letters. 10, p.20130970. 